\title{
Permanent Pacemaker Post Cardiac Surgery: where do we Stand?
}

Amer Harky ${ }^{1,2,3}$, MBChB, MSc, MRCS; Francesca Gatta ${ }^{1}$, MD; Arish Noshirwani ${ }^{1}$, MD; Shubhi Gupta ${ }^{3}$; Muhammed Kermali ${ }^{4}$, MD; Andrew D Muir ${ }^{1}$, MD

DOI: $10.21470 / 1678-9741-2020-0054$

\begin{abstract}
Cardiac arrhythmias and requirement for permanent pacemaker (PPM) post open-heart surgery are some of the complications that can contribute to significant morbidities postoperatively and delay in normal recovery if not treated promptly. The reported rate of a PPM following isolated, elective coronary artery bypass grafting is $<1 \%$, while following aortic or mitral valve surgery it is reported to be $<5 \%$. There are several perioperative factors that can contribute to the
\end{abstract}

increased likelihood of PPM requirement including preoperative rhythm, severity and location of cardiac ischaemia, perioperative variables, and the cardiac procedures performed. Optimization of such factors can possibly lead to a lower rate of PPM and, therefore, a lower rate of complications. This literature review focuses on PPM following each procedural type and how to minimize it.

Keywords: Pacemaker. Cardiac Surgery. Conduction Defects.

Abbreviations, acronyms \& symbols

\begin{tabular}{|c|c|c|c|}
\hline AR & $=$ Aortic regurgitation & LVEF & $=$ Left ventricular ejection fraction \\
\hline AS & $=$ Aortic stenosis & MVP & $=$ Mitral valve repair \\
\hline AV & $=$ Atrioventricular & MVR & $=$ Mitral valve replacement \\
\hline AVR & $=$ Aortic valve replacement & $\mathbf{N}$ & $=$ Number of patients \\
\hline bpm & $=$ Beats per minute & NYHA & $=$ New York Heart Association \\
\hline CABG & $=$ Coronary artery bypass grafting & OR & $=$ Odds ratio \\
\hline CAD & $=$ Coronary artery disease & PPM & $=$ Permanent pacemaker \\
\hline $\mathrm{Cl}$ & $=$ Confidence interval & RBBB & $=$ Right bundle branch block \\
\hline CPB & = Cardiopulmonary bypass & SAN & $=$ Sinoatrial node \\
\hline CRT & = Cardiac resynchronisation therapy & SCD & $=$ Sudden cardiac death \\
\hline DM & $=$ Diabetes mellitus & STS & $=$ Superior transseptal \\
\hline ECG & = Electrocardiogram & TIA & $=$ Transient ischemic attack \\
\hline HR & $=$ Heart rate & TS & $=$ Transseptal \\
\hline ICD & = Implantable cardioverter defibrillator & TV & $=$ Tricuspid valve \\
\hline LA & $=$ Conventional left atriotomy & TVR & $=$ Tricuspid valve repair or replacement \\
\hline LBBB & $=$ Left bundle branch block & VF & $=$ Ventricular fibrillation \\
\hline
\end{tabular}

\section{INTRODUCTION}

Postoperative complications like rhythm disturbance, conduction abnormalities, and ischaemic injury after cardiac surgery are a major source of mortality, morbidity, and a financial burden due to their requirement of permanent pacing.
Permanent pacemaker (PPM) implantation due to postoperative conduction disorders varies with the type of cardiac surgery performed:aortic valve, tricuspid valve (TV), or mitral valve repairs, a combination of either, coronary artery bypass grafting (CABG), or combined valve surgery with $C A B G$, with the rate ranging

Correspondence Address:

Amer Harky

id https://orcid.org/0000-0001-5507-5841

Department of Cardiothoracic Surgery, Liverpool Heart and Chest Hospital Thomas Drive, L14 3PE, Liverpool, United Kingdom of Great Britain and Northern Ireland

E-mail: aaharky@gmail.com 
from 0.8 to $24 \%{ }^{[1]}$. PPM may be required in $0.8 \%-3.4 \%$ of patients following $C A B G$ for sinus node dysfunction or atrioventricular (AV) conduction abnormalities. Of the patients following valve surgery due to complete or high-degree AV block-associated bradycardia ${ }^{[2]}, 2-4 \%$ are at risk of requiring a PPM. This rate rises to $20 \%$ in procedures associated with calcified aortic stenosis or TV interventions and in $20 \%$ of patients following orthotopic heart transplantation due to sinus node dysfunction ${ }^{[2]}$.

Elective valve surgery-associated bradycardia leads to the highest number of PPM implantations at a rate of 3.3\%, whilst CABG and congenital heart surgery have a PPM rate of $0.8 \%$ and $2.4 \%$, respectively ${ }^{[2]}$.

The need for postoperative pacing likely arises due to either operative procedures in close proximity to any parts of the conduction system which may cause injury or extensive coronary artery diseases, which compromises myocardial protection causing ischemic injury to the conduction system ${ }^{[3]}$. These can cause AV blocks which ultimately can lead to bradyarrhythmias and requirement for PPM.

This review aims to summarise the available literature on the rate, risk factors, and timing of PPM implantation post cardiac surgery.

\section{RISK FACTORS}

\section{Preoperative}

There are multiple preoperative risk factors that may serve a dual function as predictors of PPM. Steyers et al. ${ }^{[1]}$ found that older age, female sex, history of prior myocardial infarction, and preoperative impaired left ventricular function were indicative of the need for PPM in patients undergoing open-heart surgery.

Age is a significant risk factor; the elderly population is significantly in need of PPM after cardiac surgery with mean ages of 66-70 years in patients with PPM vs. 60.2-67.9 years in patients without $\mathrm{PPM}^{[4-9]}$. The female sex $(P=0.01$, odds ratio [OR] 5.21, $95 \%$ confidence interval [Cl] 1.48囚18.34) is another preoperative risk factor that increases the chances of PPM ${ }^{[10]}$.

The presence of preoperative rhythm and conduction abnormalities such as left bundle branch block (LBBB), bifascicular blocks, and first and second-degree heart block is associated with increased risk of PPM postoperatively (25\%, $P<0.0001$; $4 \%, P=0.017 ; 15 \%, P=0.005 ; 1 \%, P=0.08$, respectively) $)^{[11]}$. AV block in the postoperative period is associated with numerous preoperative factors including, but not limited to, being 60 years old and older, female sex, chronic kidney disease, having atrial fibrillation, New York Heart Association (NYHA) functional class III-IV, and perioperative acute myocardial infarction; all of these may indirectly increase the risk for pacemaker implantation through severe AV block onset ${ }^{[12]}$.

Presence of aortic valve diseases, stenosis, or regurgitation has been reported to be a significant contributing factor in increasing the rate of PPM postoperatively ${ }^{[11,13]}$; this is particularly relevant when there is aortic annular calcification $(P<0.001, \mathrm{OR}$ $0.05,95 \% \mathrm{Cl} 0.01-0.24)$ and in those with bicuspid aortic valve $\left(P=0.02\right.$, OR 0.24, 95\% Cl 0.07-0.84) ${ }^{[10,14]}$.
In the study by Limongelli et al..15], preoperative aortic regurgitation (OR 6.6, 95\% Cl 1.6 to $12.2 ; P<0.005)$, pulmonary hypertension (OR 12.5, 95\% Cl 3.2 to $18.3 ; P<0.005)$, and previous myocardial infarction (OR 15.2, 95\% Cl 6.3 to $19.9 ; P<0.0005)$ were also found to be significant risk factors in pacemaker requirement as they are associated with an increase in conduction abnormalities including higher degrees of AV block. Gordon et al. ${ }^{[3]}$ found active endocarditis (OR 1.7, Cl 0.92-3.0 [6.6\%, 1.1\%]) and preoperative renal failure (OR 1.6, Cl 1.0-2.6 [10.6\%, 4.9\%]) to be predictors and risk factors for PPM dependency as well.

\section{Intraoperative}

It is well established that prolonged cardiopulmonary bypass (CPB) and aortic cross-clamping times increase the likelihood of needing PPM postoperatively ${ }^{[2]}$. Merin et al. ${ }^{[1]}$ retrospectively evaluated 4,999 patients where they found the prolonged aortic cross-clamping time $(P<0.0001)$ to be a significant risk factor for permanent pacing. Erdogan et al. ${ }^{[10]}$ showed by multivariate analysis that total perfusion time $(P=0.002$, OR $1.05,95 \% \mathrm{Cl} 1.01$ 1.08 ) is an associated risk factor of PPM as it causes irreversible AV block that requires permanent pacing. Furthermore, Baerman et al. ${ }^{[16]}$ proposed the most likely mechanism of conduction defect onset to be ischemic injury, which they found is also caused by increased CPB pump time $(P<0.05)$ and increased aortic crossclamping time $(P<0.05)$.

The risk of permanent pacing varies with the type of surgery performed; Merin et al. ${ }^{[1]]}$ found aortic valve replacement (AVR) surgery $(P<0.0001)$ to be an independent risk factor that led to more people needing PPM than CABG, TV repair, and mitral valve replacement (MVR).

In addition, a multivariate analysis conducted by Piantá et al. ${ }^{[12]}$ revealed a significant association of AV block with the use of an intra-aortic balloon ( $O R=1.92 ; P=0.006)$ following $C A B G$, hence identifying a possible risk factor for PPM requirement.

\section{Postoperative}

Electrolyte disorders are considered risk factors that may predispose to permanent conduction defects in the setting of aortic valve diseases through irreversible AV block (OR 4.5, 95\% Cl 1.3 to $6.4 ; P<0.01)^{[17-18]}$, where electrolyte disorders are defined as a serum potassium of $<3.5 \mathrm{~mol} / /$, a serum magnesium of $<0.82 \mathrm{mmol} / \mathrm{l}$, and a serum calcium of $<2 \mathrm{mmol} / \mathrm{I}^{[15]}$. In such patients, the development of postoperative AV block is considered a significant risk factor for requirement of pacemaker implantation ${ }^{[9]}$, while Schurr et al. ${ }^{[5]}$ found redo-operations to increase the risk of pacemaker implantation. Perioperative risk factors have been summarised in Table 1.

\section{CORONARY ARTERY BYPASS GRAFTING AND PERMANENT PACEMAKER REQUIREMENT}

CABG is the most common cardiac procedure that is performed worldwide. The incidence of PPM following CABG varies depending on the urgency of the procedure, severity, and acuity of the ischaemia and operative factors. 
Table 1. List of preoperative, intraoperative, and postoperative risk factors.

\begin{tabular}{|c|c|c|}
\hline Preoperative risk factors & Intraoperative risk factors & Postoperative risk factors \\
\hline $\operatorname{Age}^{[1]}$ & Use of intra-aortic balloon ${ }^{[20]}$ & Electrolyte disorders ${ }^{[22]}$ \\
\hline $\operatorname{Sex}^{[1]}$ & Diuretic use ${ }^{[2]}$ & Atrioventricular block ${ }^{[41]}$ \\
\hline History of prior myocardial infarction ${ }^{[1]}$ & Cardiopulmonary bypass duration ${ }^{[17]}$ & Redo operations ${ }^{[42]}$ \\
\hline Preoperative left ventricular function ${ }^{[1]}$ & Total perfusion time ${ }^{[30]}$ & \\
\hline Rhythm and conduction abnormalities $^{[11]}$ & Cross-clamping time ${ }^{[11]}$ & \\
\hline$A \mathrm{VR}^{[11]}$ & Type of surgery ${ }^{[11]}$ & \\
\hline \multicolumn{3}{|l|}{ Antiarrhythmics ${ }^{[11]}$} \\
\hline \multicolumn{3}{|l|}{ Chronic kidney disease ${ }^{[20]}$} \\
\hline \multicolumn{3}{|l|}{ Atrial fibrillation ${ }^{[20]}$} \\
\hline \multicolumn{3}{|l|}{ NHYA functional class III-IV[20] } \\
\hline \multicolumn{3}{|l|}{ Pulmonary hypertension ${ }^{[22]}$} \\
\hline \multicolumn{3}{|l|}{ Preoperative aortic regurgitation ${ }^{[22]}$} \\
\hline \multicolumn{3}{|l|}{ Active endocarditis ${ }^{[3]}$} \\
\hline \multicolumn{3}{|l|}{ Renal failure ${ }^{[22]}$} \\
\hline \multicolumn{3}{|l|}{ Interventricular septum diameter ${ }^{[23]}$} \\
\hline \multicolumn{3}{|l|}{ Low ejection fraction ${ }^{[29]}$} \\
\hline \multicolumn{3}{|l|}{ Use of calcium channel blockers ${ }^{[29]}$} \\
\hline \multicolumn{3}{|l|}{ Annular calcification ${ }^{[29]}$} \\
\hline Bicuspid aortic valve ${ }^{[29]}$ & & \\
\hline
\end{tabular}

Transient minor conduction disturbances are relatively common after $C A B G$, however, in some patients, persistent bradyarrhythmia requires urgent treatment with a PPM.

Following isolated CABG, the incidence of PPM varies between 0.4 to $2 \%$.

Age above 60 years plays an important role in increasing the rate of post-CABG PPM implantation ${ }^{[4,11,12,17]}$. Emlein's study compared 13 patients who required PPM post CABG to 490 patients who did not have any postoperative bradyarrhythmia; the former group had a mean age of 69.2 years vs. 62.8 years of the latter ${ }^{[17]}$. Piantá considered a sample of 3,532 CABG: $0.25 \%$ of these patients required PPM and were associated with age above 60 years (OR 2.34) $)^{[12]}$. Onalan studied the predictors of pacing dependency after coronary, mitral, and aortic valve surgeries, and the mean age of these patients was $68 \pm 11$ years ${ }^{[18]}$. Merin conducted a study on 4,999 patients of which 3,448 (69\%) underwent CABG. The 72 cases who required a PPM had a mean age of $67 \pm 10$ years vs. $64 \pm 11$ years for non-PPM patients. Thirtytwo patients (44\%) were over 70 years of age vs. 1,521 (31\%) of non-PPM patients ${ }^{[11]}$. Raza analysed a sample of 6,268 patients with an incidence of PPM of 2.2\% (141 patients): 4,678 underwent CABG and, of these, 43 (0.9\%) required PPM with a mean age of $69 \pm 9$ years vs. $66 \pm 10$ years of non-PPM patients ${ }^{[4]}$.

Similarly, a higher NYHA class is associated with a higher rate of PPM postoperatively. In the Piantá's study, the association of PPM and functional classes III and IV of NYHA had an OR of $1.43^{[12]}$. The association between NYHA and the incidence of PPM was also proven by Merin; 39 out of 72 (57\%) PPM cases had NYHA classes III and IV[11-12]

Specific groups of patients appear to have a higher association with postoperative conduction defects requiring PPM. This is summarised in Table 2.

Coronary artery pathology location has a direct effect on the incidence of conduction disturbances following CABG and, therefore, the rate of PPM implantation. Caspi et al. ${ }^{[19]}$ reported that patients with left main coronary artery stenosis in conjunction with total occlusion of a dominant right coronary artery are at higher risk of developing postoperative AV block (18 out of 56 patients developing AV block in a database of 348 consecutive patients that had (ABG). In addition, the presence 
Table 2. List of risk factors for greater incidence of PPM postoperatively.

\begin{tabular}{|c|c|}
\hline Risk factors & Studies \\
\hline \multirow{2}{*}{ Renal failure } & Piantá: OR 2.05 $5^{[12]}$ \\
\hline & Merin: 13\% PPM vs. 9\% non-PPM ${ }^{[11]}$ \\
\hline \multirow{2}{*}{ Antiarrhythmics preoperatively } & Merin: 21\% PPM vs. 7\% non-PPM ${ }^{[11]}$ \\
\hline & Baraki: $8 \%$ of PPM ${ }^{[40]}$ \\
\hline $\begin{array}{l}\text { Abnormal ECG preoperatively } \\
\text { I or Il-degree AV block } \\
\text { AV block } \\
\text { LBBB } \\
\text { Bifascicular block }\end{array}$ & $\begin{array}{c}\text { Emlein: LBBB } 5 \text { of } 13 \text { PPM vs. } 6 \text { of } 490 \text { non-PPM }{ }^{[17]} \\
\text { Glikson: I/II-degree AV block } 42 \% \text { of PPM } \\
\text { LBBB 17\% of PPM }{ }^{[23]} \\
\text { Merin: AV block 15\% PPM vs. 6\% non-PPM } \\
\text { I/II-degree AV block 15\% PPM vs. 5.7\% non-PPM } \\
\text { Bifascicular block 4\% PPM vs. 1\% non-PPM } \\
\text { LBBB 25\% PPM vs. 2.6\% non-PPM }{ }^{[11]} \\
\text { Al-Ghamdi: LBBB P<0.05[28] } \\
\text { Turkann: conduction abnormality OR 4.429 }\end{array}$ \\
\hline
\end{tabular}

$\mathrm{AV}=$ atrioventricular; $\mathrm{ECG}=$ electrocardiogram; $\mathrm{LBBB}=$ left bundle branch block; $\mathrm{OR}=$ odds ratio; $\mathrm{PPM}=$ permanent pacemaker

of an ungraftable right coronary artery was significantly more frequent in patients with AV block ${ }^{[19]}$.

Mosseri et al. ${ }^{[20]}$ reported that diseases in the left anterior descending coronary artery at the origin of the first septal branch had a higher rate of postoperative bradyarrhythmia. Those findings were supported by the study from Mustonen et al. ${ }^{[21]}$, which confirmed the correlation between coronary artery anatomy and post-CABG conduction disturbances (left main coronary artery stenosis noted in 14 out of 52 patients requiring PPM after CABG vs. seven in 47 patients who were bradyarrhythmia-free after (ABG).

Operatively, the use of cardioplegia, duration of CPB, and aortic cross-clamping time are associated with an increased rate of postoperative bradyarrhythmias. Gundry et al. ${ }^{[22]}$ compared all patients undergoing CABG after either crystalloid or blood cardioplegia. The former was used in 179 patients: 23\% of such patients developed conduction disturbances and four patients required PPM implantation before discharge. Those results were also supported by a different study from Merin et al. ${ }^{[1]}$. In the study of Gundry et al. ${ }^{[22]}$, blood cardioplegia was used in 289 patients: 141 (49\%) developed arrhythmias and 12 of them needed a PPM ${ }^{[22]}$. Eight years later, Gundry et al. ${ }^{[22]}$ conducted a new study using 2:1 blood cardioplegia rather than 4:1 blood cardioplegia in 90 consecutive CABG patients. Only eight of the 90 patients (9\%) had any conduction disturbance and only one required a $P$ PM.

In 1998, Mustonen compared the CPB time between new conductive defects after CABG and absence of any

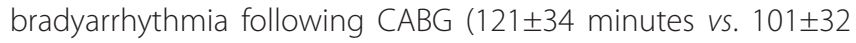
minutes, respectively), as well as the aortic cross-clamping time $(53 \pm 17 \text { minutes vs. } 44 \pm 19 \text { minutes, respectively })^{[21]}$. Additionally, a higher incidence of PPM following prolonged CPB and aortic cross-clamping times has also been reported by others ${ }^{[4,11,16,23]}$.
In summary, the rate of PPM implantation following CABG is increased in older age, NYHA class III-IV, renal failure, use of preoperative antiarrhythmics and electrocardiogram disturbances, specific coronary artery pathology, blood and cold cardioplegia, and prolonged CPB and aortic cross-clamping times. Therefore, optimization of such factors such as restoration of normal sinus rhythm, shorter operative times, or off-pump surgeries can reduce the need for PPM postoperatively.

\section{VALVE SURGERY AND PERMANENT PACEMAKER REQUIREMENT}

Disturbances of the conduction system are established and reported complications after cardiac valve surgery. The literature suggests that a PPM is required in approximately $6 \%$ of cases; this rate varies depending on the severity of the valve disease and multivalve surgeries.

The aetiology of such high PPM requirement is multifactorial, and this includes older age, preoperative comorbidities, such as diabetes mellitus and electrolyte disturbances, impaired ejection fraction, and the presence of coronary artery disease, preoperative conduction disturbances, and use of antiarrhythmics. Along with these, intraoperative variables play a significant role, particularly the CPB and aortic cross-clamping times, cardioplegia, and valve type. Direct damage of the conduction system can occur during surgical manipulation, specifically during aortic valve surgery as the $\mathrm{AV}$ bundle runs at the top of the septum next to the aortic annulus. The specific variables have been reported in Tables 3 and 4.

The main indications for PPM in a patient with heart valve surgery are second- and third-degree AV block. Second-degree block occurred in $12.4-44 \%$ of patients reported in different studies, while third-degree heart block occurred in $42.3-87.5 \%$ of patients in the same studies ${ }^{[5,15,24]}$. 
Table 3. List of preoperative variables; PPM vs. non-PPM

\begin{tabular}{|c|c|c|c|c|c|c|}
\hline Variables $\begin{array}{r}\text { Author and } \\
\text { year }\end{array}$ & $\begin{array}{l}\text { Limongelli, } \\
2003^{[15]}\end{array}$ & $\begin{array}{c}\text { Elahi, } \\
2005^{[43]}\end{array}$ & $\begin{array}{l}\text { Dawkins, } \\
2008^{[13]}\end{array}$ & $\begin{array}{l}\text { Schurr, } \\
2010^{[5]}\end{array}$ & $\begin{array}{l}\text { Huynh, } \\
2010^{[6]}\end{array}$ & $\begin{array}{c}\text { Klapkowski, } \\
2016^{[42]}\end{array}$ \\
\hline Total cohort & 276-3.2\% PPM & 782 & $354-8.5 \%$ PPM & 3534-6.6\% PPM & 214-7.2\% PPM & $159-6.9 \%$ \\
\hline Age & 65.7 vs. 57.5 & - & $66 \pm 13(\mathrm{PPM})$ & $66 \pm 14$ vs. $60.2 \pm 13.9$ & $70 \pm 10$ vs. $67.9 \pm 12$ & 59.2 vs. 65.7 \\
\hline CAD & $22 \%$ vs. $3 \%$ & - & - & - & $53.3 \%$ vs. $55.6 \%$ & $27.3 \%$ vs. $25 \%$ \\
\hline LVEF & $45.6 \%$ vs. $50.4 \%$ & $<35 \%$ PPM & - & $53.6 \pm 13.5$ vs. $57 \pm 13.4$ & $54.3 \pm 8 \%$ vs. $52 \pm 13 \%$ & - \\
\hline NYHA class & 2.61 vs. 2.44 & - & - & - & - & - \\
\hline DM & $22 \%$ vs. $15 \%$ & - & - & - & $33.3 \%$ vs. $25 \%$ & $27.3 \%$ vs. $24.3 \%$ \\
\hline Preop. LBBB & - & $>$ PPM & - & $10.2 \%$ vs. $5.2 \%$ & $6.7 \%$ vs. $2.6 \%$ & $0 \%$ vs. $3.4 \%$ \\
\hline Preop. RBBB & - & - & - & $12.3 \%$ vs. $4.1 \%$ & $6.7 \%$ vs.3.3\% & $9.1 \%$ vs. $0.7 \%$ \\
\hline AV conduction disorder & $12 \%$ vs. $3 \%$ & - & - & & $20 \%$ vs. $3.1 \%$ & - \\
\hline Preop. sinus rhythm & - & - & - & - & $93.3 \%$ vs. $94.8 \%$ & $90.9 \%$ vs. $84.4 \%$ \\
\hline Antiarrhythmics & $88 \%$ vs. $60 \%$ & - & - & - & - & - \\
\hline $\begin{array}{c}\text { Preop. electrolyte } \\
\text { disorders }\end{array}$ & $12.5 \%$ vs. $2 \%$ & - & - & - & - & - \\
\hline AS & $22 \%$ vs. $40 \%$ & - & $55 \%$ vs. $61 \%$ & - & - & $54.4 \%$ vs. $73 \%$ \\
\hline$A R$ & $67 \%$ vs. $28 \%$ & - & $38 \%$ vs. $17 \%$ & - & $66.7 \%$ vs. $63 \%$ & $9.1 \%$ vs. $7.4 \%$ \\
\hline$A S+A R$ & $11 \%$ vs. $32 \%$ & - & $0 \%$ vs. $6 \%$ & - & - & $18.2 \%$ vs. $16.9 \%$ \\
\hline
\end{tabular}

$A R=$ aortic regurgitation; $A S=$ aortic stenosis; $A V=$ atrioventricular; $C A D=$ coronary artery disease; $D M=$ diabetes mellitus; $L B B B=l$ eft bundle branch block; LVEF=left ventricular ejection fraction; NYHA=New York Heart Association; PPM=permanent pacemaker; RBBB=right bundle branch block

Table 4. List of intraoperative variables; PPM vs. non-PPM.

\begin{tabular}{|c|c|c|c|c|c|c|}
\hline Variables & $\begin{array}{l}\text { Limongelli, } \\
2003^{[15]}\end{array}$ & $\begin{array}{c}\text { Elahi, } \\
2005^{[43]}\end{array}$ & $\begin{array}{l}\text { Dawkins, } \\
2008^{[13]}\end{array}$ & $\begin{array}{l}\text { Schurr, } \\
2010^{[5]}\end{array}$ & $\begin{array}{l}\text { Huynh, } \\
2010^{[6]}\end{array}$ & $\begin{array}{l}\text { Klapkowski, } \\
2016^{[42]}\end{array}$ \\
\hline $\begin{array}{l}\text { Cardiopulmonary } \\
\text { bypass time (min) }\end{array}$ & 112 vs. 91 & + 100 PPM & $72 \pm 34$ vs. $66 \pm 25$ & $137 \pm 63.4$ vs. $101 \pm 31.8$ & $157 \pm 49$ vs. $144 \pm 43$ & 135.5 vs. 113.9 \\
\hline $\begin{array}{l}\text { Aortic cross-clamping } \\
\text { time (min) }\end{array}$ & 72 vs. 61 & + 70 PPM & $54 \pm 23$ vs. $51 \pm 20$ & $80.5 \pm 37.8$ vs. $61 \pm 62.6$ & $125 \pm 43$ vs. $114 \pm 36$ & 89.5 vs. 73.4 \\
\hline Cold cardioplegia & $100 \%$ vs. $83 \%$ & - & - & - & - & - \\
\hline Mechanical valve & - & - & $44.8 \%$ vs. $42.8 \%$ & - & $20 \%$ vs. $17.7 \%$ & $45.5 \%$ vs. $28.4 \%$ \\
\hline Bioprosthetic valve & - & - & $55 \%$ vs. $57.18 \%$ & - & $80 \%$ vs. $82.2 \%$ & $54.5 \%$ vs. $71.6 \%$ \\
\hline
\end{tabular}

PPM=permanent pacemaker

In 2010, Nardi et al. ${ }^{[24]}$ showed that greater preoperative end-systolic diameter and left ventricular septum hypertrophy correlate directly with a higher incidence of PPM. Several studies have reported variable rates of PPM post mitral valve surgery, ranging from $2.6 \%$ to $7.7 \%$. Table 5 is a summary of key literature studies reporting outcomes of PPM in mitral valve surgery considering the approach to the mitral valve (transseptal vs. superior transseptal vs. conventional left atriotomy). This can have a direct correlation with the incidence of PPM postoperatively. However, in the nine studies reported, no significant difference was detected, perhaps due to the samples being non-homogeneous in number or the cohort being small.

Meimoun et al. ${ }^{[25]}$ examined mitral valve repair in 115 patients; three patients (2.6\%) needed a PPM, but neither the preoperative variables nor the mitral procedure itself was related to the postoperative conduction disturbances. DeRose et al. ${ }^{[26]}$ reported that the practice of atrial fibrillation ablation and NYHA class III/IV were associated with an increased risk for permanent pacing postoperatively. 
The incidence of PPM implantation in isolated TV repair is less well known. Studies have shown that the rate of PPM is the highest after TV surgery compared to other cardiac surgery procedures $^{[3,27]}$.

Jokinen's study, in 2009, showed a correlation between NYHA class III/IV and PPM; moreover, the need is not confined to the immediate postoperative period but it extends throughout the follow-up period ${ }^{[7]}$.

It is of interest to note that the multicentre analysis conducted by Mar et al. ${ }^{[8]}$ in 2017 did not show a significant correlation between age, gender, and comorbidities and the need for PPM. However, aorta cross-clamping time of $>60$ minutes was identified as a risk factor for PPM requirement. Nevertheless, isolated TV surgery occurred in 14\% of patients (32 out of 237) and only two required PPM. Based on such controversial reported

Table 5. Rate of PPM in mitral valve surgery considering the approach to the mitral valve.

\begin{tabular}{|c|c|c|}
\hline Author and year & $\begin{array}{c}\text { Patients' } \\
\text { characteristics }\end{array}$ & $\begin{array}{c}\text { Outcome } \\
\text { (PPM implantation) }\end{array}$ \\
\hline $\begin{array}{l}\text { Aydin, } \\
2014^{[44]}\end{array}$ & $\begin{array}{c}N=91 \\
S T S=47 \\
L A=44\end{array}$ & $\begin{aligned} \mathrm{STS} & =5(10.6 \%) \\
\mathrm{LA} & =2(4.5 \%)\end{aligned}$ \\
\hline $\begin{array}{l}\text { Garcia-Villarreal, } \\
2003^{[45]}\end{array}$ & $\begin{array}{l}N=247 \\
S T S=128 \\
L A=119\end{array}$ & $\begin{aligned} \text { STS } & =2(1.6 \%) \\
L A & =6(5 \%)\end{aligned}$ \\
\hline $\begin{array}{l}\text { Gaudino, } \\
1997^{[30]}\end{array}$ & $\begin{array}{l}N=146 \\
S T S=63 \\
L A=63\end{array}$ & $\begin{array}{l}\mathrm{STS}=2(3.2 \%) \\
\mathrm{LA}=3(4.8 \%)\end{array}$ \\
\hline $\begin{array}{l}\text { Lukac, } \\
2007^{[46]}\end{array}$ & $\begin{array}{c}N=577 \\
S T S=150 \\
L A=427\end{array}$ & $\begin{aligned} \text { STS } & =17(11.3 \%) \\
\text { LA } & =27(6.3 \%)\end{aligned}$ \\
\hline $\begin{array}{l}\text { Masuda, } \\
1996^{[47]}\end{array}$ & $\begin{array}{l}N=152 \\
S T S=83 \\
L A=69\end{array}$ & $\begin{array}{l}\text { STS }=6 \% \\
L A=4 \%\end{array}$ \\
\hline $\begin{array}{l}\text { Nienaber, } \\
2006^{[48]}\end{array}$ & $\begin{array}{l}N=531 \\
T S=258 \\
L A=273\end{array}$ & $\begin{array}{l}\mathrm{TS}=25(10.5 \%) \\
\mathrm{LA}=13(5.1 \%)\end{array}$ \\
\hline $\begin{array}{l}\text { Rezahosseini, } \\
\text { 2015 }\end{array}$ & $\begin{array}{l}\mathrm{N}=815 \\
\mathrm{TS}=163 \\
\mathrm{LA}=652\end{array}$ & $\begin{array}{l}\mathrm{TS}=1(0.61 \%) \\
\mathrm{LA}=2(0.3 \%)\end{array}$ \\
\hline $\begin{array}{l}\text { Tenpaku, } \\
\text { 2000 }\end{array}$ & $\begin{array}{c}N=95 \\
T S=40 \\
S T S=30 \\
L A=22\end{array}$ & $\begin{array}{c}\mathrm{TS}=1(2.5 \%) \\
\mathrm{STS}=1(3.3 \%) \\
\mathrm{LA}=0\end{array}$ \\
\hline $\begin{array}{l}\text { Utley, } \\
1995^{[51]}\end{array}$ & $\begin{array}{l}\mathrm{N}=149 \\
\mathrm{TS}=37 \\
\mathrm{STS}=46 \\
\mathrm{LA}=66\end{array}$ & $\begin{array}{c}\text { TS }=6(18 \%) \\
\text { STS }=8(18 \%) \\
\text { LA }=6(9 \%)\end{array}$ \\
\hline
\end{tabular}

$\mathrm{LA}=$ conventional left atriotomy; $\mathrm{N}=$ number of patients; PPM=permanent pacemaker; STS=superior transseptal; TS=transseptal outcomes, a larger trial is required to confirm the findings in this cohort of patients.

\section{COMBINED PROCEDURES, ARE THE RISKS HIGHER?}

It is with no doubt that complex cardiac surgeries, especially multivalve surgeries, are associated with a higher rate of PPM insertion due to the possible iatrogenic damage to the conduction system, involvement of such conduction system into the valve pathologies, or ischaemic damage to the conduction system.

A systematic review of 14,054 patients from nine studies was aimed at comparing the rate of PPM in patients undergoing CABG with valve surgery and/or combined valve surgery. Overall, the incidence of PPM following multiple valve surgery seemed to be higher than CABG + valve surgery, the former ranging from $5 \%$ to $90 \%$, the latter from $4.34 \%$ to $86.84 \%$. In particular, if we compare the two incidences respectively in the studies reported: Elahi $8 \%$ vs. $4.34 \%$, Jokinen $49.5 \%$ vs. $21.6 \%$, Huynh $33.3 \%$ vs. $7.14 \%$, Schurr $90 \%$ vs. $86.84 \%$, and Mar 34.19\% vs. 22.97\%, Glikson's study was the only one having the opposite trend, 13\% PPM post CABG + valve vs. $5 \%$ post-combined valve ${ }^{[22]}$. Risk factors for PPM implantation were older age, preoperative comorbidities, conduction disturbances and antiarrhythmics preoperatively, impaired systolic function and coronary artery disease, higher NYHA class, and intraoperative factors.

Glikson et al. ${ }^{[23]}$ analysed their cohort of PPM insertion in 120 patients; 28 patients (23\%) had AVR, six patients (5\%) had MVR, six patients (5\%) had AVR plus MVR, 30 patients (25\%) had CABG, and 16 patients (13\%) had combined valve and CABG.

In 2006, Elahi et al. ${ }^{[9]}$ reported their PPM insertion rate in their institute that covered 129 patients out of 2,392. It was noted that patients that had a valve or combined surgeries had a higher rate of PPM ( $n=75,5.35 \%$ single valve surgery; $n=18,8 \%$ in multiple valve surgeries; $n=28,4.34 \%$ in CABG + single valve surgery).

In 2009, Jokinen analysed two groups of patients with regards to the need for PPM postoperatively ${ }^{[7]}$. This was the case in $20 \%$ of patients $(n=5)$ in isolated valve surgery, $8.3 \%(n=1)$ in AVR + TV surgery, 19.5\% ( $n=16)$ in MVR/mitral valve repair (MVP) + TV surgery, 30\% ( $n=6)$ in AVR + MVR/MVP + TV surgery, $21.6 \%$ $(n=8)$ in valve surgery $+C^{-} A B G^{[7]}$.

In 2010, Huynh focused on the incidence of PPM in patients undergoing AVR 5.5\% ( $n=6), A V R+C A B G 7.14 \%(n=7)$, and AVR + MVR 33.3\% (n=2) ${ }^{[6]}$. In 2010, Schurr analysed the number of patients who required PPM after several surgical procedures ${ }^{[5]}$. His team found that for AVR + mitral valve repair, $78.57 \%(n=11)$ required $P P M$; for $A V R+M V R, 86.66 \%(n=13)$ required $P P M$; for $A V R+C A B G, 86.84 \%(n=99)$ required PPM; for $A V R+$ ventricular septal defect/atrial septal defect closure, $100 \%(n=17)$ of patients required PPM; and for AVR + previous mitral valve surgery, 100\% $(n=4)$ of patients required PPM.

In 2011, Raza conducted a similar study ${ }^{[4]}$. The team showed that following a CABG, $0.9 \%(n=43)$ required PPM; following AVR $+C A B G, 6 \%(n=64)$ required PPM; following MVR + CABG, 7.6\% $(n=14)$ required PPM; following valve repair + CABG, 1.2\% $(n=2)$ required PPM; following great vessel repair + $C A B G, 0$ out of 57 patients required PPM; following double valve + CABG, 16.3\% 
$(n=8)$ required PPM; and following all other surgery, 13.9\% $(n=10)$ of patients required PPM.

In 2016, Al-Ghamdi considered the incidence of patients requiring PPM following surgery and found the following: CABG alone (3-0.52\%), valve alone (19-2.63\%), and combined surgery $(2-1.6 \%)^{[28]}$.

In 2017, Mar et al. ${ }^{[8]}$ analysed the incidence of PPM in patients undergoing TV surgery associated with other cardiac surgery procedures, and found that the incidence for patients undergoing a tricuspid valve repair or replacement (TVR) was $6.25 \%(n=2)$, none of the seven patients undergoing a TVR + AVR required a PPM, TVR + MVR was $35 \%(n=35)$, TVR + CABG was $10 \%(n=1)$, TVR + AVR + CABG was 33.3\% $(n=1)$, TVR + MVR + CABG was $19.14 \%(n=9)$, TVR + AVR + MVR was $40.9 \%(n=9)$, and $T V R+A V R+M V R+C A B G$ was $42.85 \%(n=6)$.

As such, the incidence of a PPM seems to be higher in combined procedures, particularly when the TV is involved. However, several factors increase the risk of postoperative bradyarrhythmias requiring PPM, such as age, NYHA class III/IV, impaired ejection fracture, preoperative conduction disturbances, and prolonged CPB and aorta cross-clamping times.

\section{REDO CARDIAC SURGERY AND RISK OF PERMANENT PACEMAKER REQUIREMENT}

The incidence of PPM following redo cardiac surgery is less well known compared to the one of single/multiple procedures.

For this systematic review, six articles with a total of 4,619 patients, addressing the number of PPM and the predictor factors following redo surgery, were considered.

Only one article addresses exclusively the rate of PPM following reoperation ${ }^{[29]}$.

The rest of the mentioned articles do not address the single rate of PPM after reoperation. In Lewis' database, the incidence of PPM in redo cases was 9.7\%[20].

In 2006, Elahi conducted a study on PPM after cardiac surgery, including redo cases (239 redos and 1,838 first-time operations); in the former, 19 (7.94\%) patients had a PPM; in the latter 110 (5.98\%) required PPM ${ }^{[9]}$. Jokinen et al..$^{[7]}$ conducted a similar study; 21 patients had redo surgery and three patients (14.28\%) required PPM. On the other hand, 115 had first-time surgery with a PPM incidence of 25 (21.73\%). In 2016, from AlGhamdi's cohort of 1,234 patients, 313 were redo surgeries and 12 of them $(0.97 \%)$ required PPM vs. eight (0.86\%) of the first-time operation patients ${ }^{[28]}$. In 2017, Mar et al. database included 45 redo surgeries with a PPM incidence of 13 (28.88\%) and 192 firsttime surgery with a rate of 52 patients $(27 \%)^{[30]}$. Finally, Turkkan et al. ${ }^{[2]}$ considered 62 patients who required PPM after cardiac surgery; three of them were redo cases.

\section{INDICATIONS FOR PERMANENT PACEMAKER REQUIREMENT}

The indications of PPM following cardiac surgery can be split into three categories: sinoatrial node dysfunction, AV conduction block, and fascicular block ${ }^{[3,31]}$.

These can be exhibited clinically as symptomatic bradycardia (syncope) or a heart rate of $<40$ beats per minute, second- and third-degree heart block persisting for more than 48 hours, or intermittent heart block. In cases of a slow self-rhythm of $>50$ beats per minute, it is recommended to monitor and assess for deterioration. If sinus rhythm is maintained immediately after surgery, there is no need for PPM ${ }^{[5,32]}$. This is summarised in Figure 1.

Table 6 describes the class of indication for each of the categories. Class I includes conditions in which it is largely agreed that a PPM should be implanted; class II involves conditions in which pacemakers are frequently implanted but their need is disrupted; and class III are conditions in which it is agreed that permanent pacing is not necessary ${ }^{[31,33]}$.

Before insertion of a PPM, several factors must be checked to avoid any complications or risks to the procedure. These include, but are not limited to, checking for any underlying electrical instability which could compromise the procedure. These can come in the form of electrolyte imbalances, active myocardial ischaemia, or hypoxaemia ${ }^{[34]}$. In addition, infection markers should be checked as active infection is a potential reason for delayed implantation ${ }^{[11]}$.

PPM insertion is not risk free and several studies have extensively reported on risks associated with inserting PPM during the postoperative period. These can be split into major and minor complications. Major complications include death, cardiac perforation, cardiac tamponade, and malfunctions of the generator or lead, among others. Minor complications include, but are not limited to, cellulitis, local pain, and peripheral nerve injury ${ }^{[35-38]}$. Table 7 summarises these complications.

\section{TIMING OF PERMANENT PACEMAKER IMPLANTATION POSTOPERATIVELY}

The main benefits of early PPM implantation includes early mobilization and recovery, shorter intensive care unit stay, and early discharge from hospital leading to economic benefits for the hospita[ [1,39]. The risk of sudden death due to unpredictable AV block, drug-induced arrhythmias, and asystole in early postoperative periods could be reduced ${ }^{[1,39]}$. However, liberal PPM implantation is costly and may lead to avoidable pacemaker complications ${ }^{[1,39]}$. This is why predictors are necessary to provide early treatment to high-risk patients.

Some evidene suggest that $45 \%$ of patients to be pacemaker dependents at time of follow-up following their open-heart surgery ${ }^{[1]}$; however, Huynh et al. ${ }^{[6]}$ reported $70 \%$ of patients undergoing aortic and mitral valve surgery to be pacemaker dependents. Furthermore, Merin et al. ${ }^{[1]]}$ found no correlation between early ( $\leq 5$ days) or late implantation to pacemaker dependency at late follow-up. These evidences suggest a controversial relationship between the timing of pacemaker implantation and long-term dependency as described by Steyers et al. ${ }^{[1]}$ in their systematic review.

Kim et al. recommend PPM implantation by day seven if the AV block is not resolved by 48 hours ${ }^{[40]}$. Baraki et al. ${ }^{[39]}$ also found that if the AV block persists for longer than 48 hours, patients should receive early implantation; their long-term follow-up showed a 56\% pacemaker dependency. Berdajs et al. ${ }^{[41]}$ support this conclusion where patients with AV block should receive PPM 


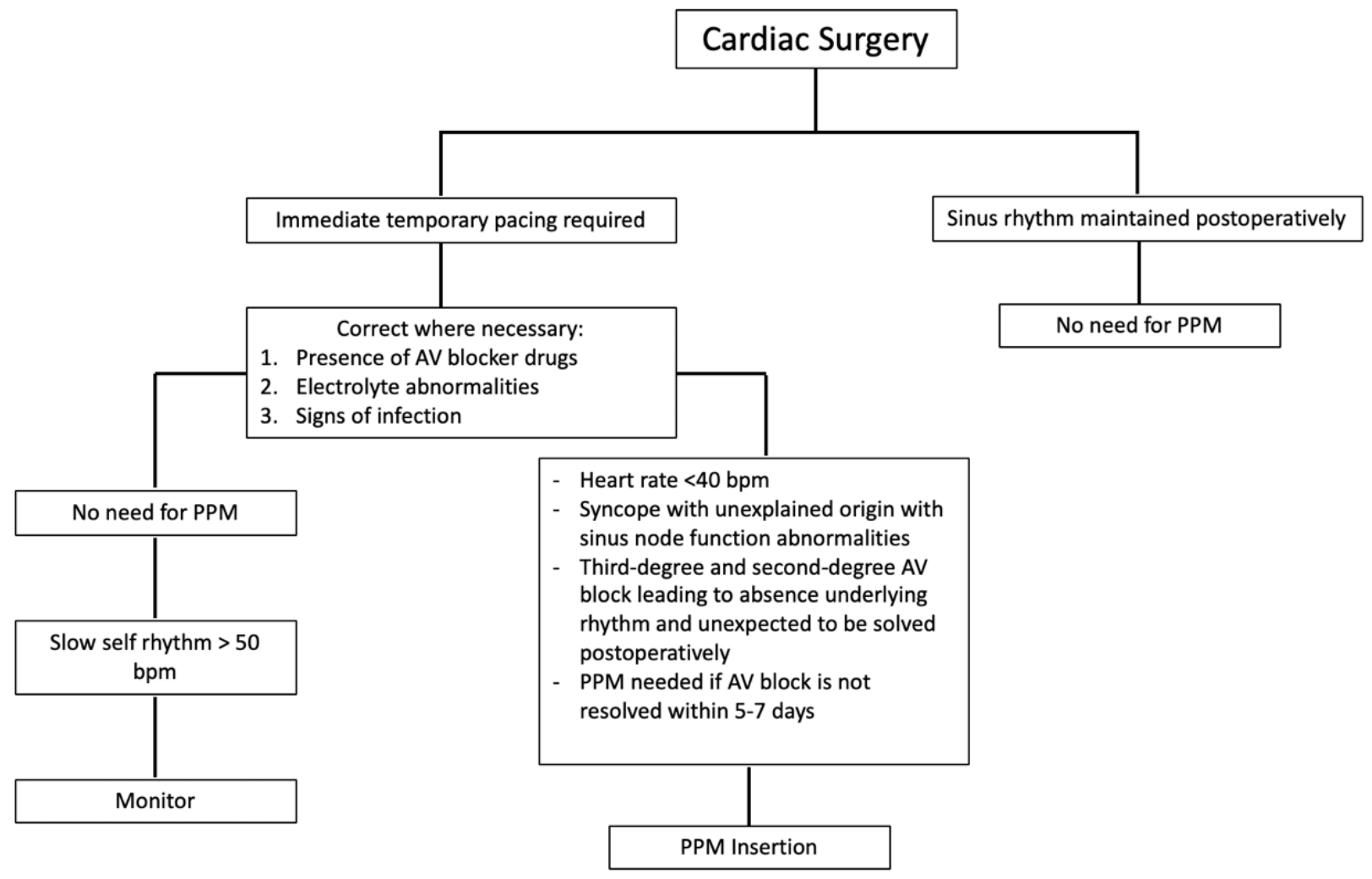

Fig. 1 - Flow chart of how permanent pacemaker (PPM) is indicated post cardiac surgery. ${ }^{[32,41]} \mathrm{AV}=$ atrioventricular; bpm $=$ beats per minute

Table 6. Post-cardiac surgery indications for PPM according to class of indication*[31,33].

\begin{tabular}{|c|c|}
\hline Disorder & Class of indication \\
\hline \multirow[t]{3}{*}{ Sinoatrial node dysfunction } & I: SAN dysfunction with documented symptomatic bradycardia \\
\hline & II: SAN with HR < 40 bpm; no clear association between symptoms and bradycardia \\
\hline & III: No symptoms \\
\hline \multirow[t]{3}{*}{ AV block } & $\begin{array}{l}\text { I: Symptomatic third or second-degree AV block, asymptomatic third-degree heart block with } \\
\qquad 40 \text { bpm or consequence of His-bundle ablation }\end{array}$ \\
\hline & II: Asymptomatic second-degree type II or third-degree block with HR > 40 bpm \\
\hline & III: First-degree AV block or asymptomatic second-degree type I AV block \\
\hline \multirow[t]{3}{*}{ Bifascicular or trifascicular block } & $\begin{array}{l}\text { I: Fascicular block with intermittent third-degree heart block associated with symptoms or } \\
\text { second-degree type II block with or without symptoms }\end{array}$ \\
\hline & $\begin{array}{c}\text { II: His-ventricular intervals }>100 \text { msec or fascicular block associated with syncope that cannot } \\
\text { be ascribed to other causes }\end{array}$ \\
\hline & $\begin{array}{l}\text { III: Asymptomatic fascicular block or fascicular block associated with first-degree AV node } \\
\text { block }\end{array}$ \\
\hline
\end{tabular}

*According to classification system established by the Joint American College of Cardiology-American Heart Association Task Force. $\mathrm{AV}=$ atrioventricular; bpm=beats per minute; $\mathrm{HR}=$ heart rate; $\mathrm{PPM}=$ permanent pacemaker; $\mathrm{SAN}=$ sinoatrial node 
Table 7. List of complications upon insertion of PPM post cardiac surgery ${ }^{[35-38]}$.

\begin{tabular}{l|c}
\hline Major complications & Minor complications \\
\hline Death & Cellulitis \\
\hline Cardiac perforation & Local pain \\
\hline Cardiac tamponade & Peripheral nerve injury \\
\hline Generator or lead malfunction — lead break, bad connection lead-generator & Superficial phlebitis \\
\hline Infection such as lead endocarditis, pocket infection & Uncomplicated hematomas \\
\hline Haematoma & Stitch abscess \\
\hline Lead dislodgment — Twiddler's syndrome & \\
\hline Pneumothorax & \\
\hline Haemothorax & \\
\hline Pre-erosion or erosion of pocket & \\
\hline Thromboembolic event —TIA, stroke, pulmonary thromboembolism, thrombosis, \\
deep venous thrombosis & \\
\hline Pacemaker syndrome & \\
\hline PPM-perant pacmat;A & \\
\hline
\end{tabular}

PPM=permanent pacemaker; $\mathrm{TI} A=$ transient ischemic attack

implantation not beyond the first week. Merin et al. ${ }^{[1]}$ recommend earlier implantation by postoperative day five for patients who are pacemaker dependent after surgery and for those whose spontaneous rhythm does not recover, especially for patients at high risk for conduction disturbances, such as patients with preexisting conduction disturbance type of surgery, especially AVR. The proposed range for PPM implantation seems to be no more than the first week, aside from exceptions where physicians may delay implantation due to fluctuating conduction disorders, questionable indication, or active infections ${ }^{[11]}$.

The decision of PPM implantation, as well as timing, is left to the physician's discretion; however, there is a general consensus supporting early implantation in patients.

\section{IMPLANTABLE CARDIOVERTER DEFIBRILLATOR AND CARDIAC RESYNCHRONISATION THERAPY}

Appropriate use of heart pacing devices is essential for optimal treatment of cardiac patients. Implantable cardioverter defibrillator (ICD), cardiac resynchronisation therapy (CRT), and PPM are frequently used devices, each with their own specific indication.

Ventricular arrhythmias are a leading cause of sudden cardiac death (SCD), covering a spectrum of severity from asymptomatic ventricular contractions to ventricular fibrillation (VF). ICDs are considered for primary and secondary prevention of these SCDs. Primary prevention works in individuals who have not had an episode of ventricular tachycardia, VF, or resuscitated cardiac arrest; whereas secondary prevention works in patients who have survived aforementioned events. ICDs are preferred in situations such as coronary artery disease, non-ischaemic dilated, hypertrophic, arrhythmogenic right ventricular cardiomyopathy, and long-QT syndrome.
Conversely, CRT is the recommended pacing treatment in cases of severe ventricular systolic dysfunction where left ventricular ejection fraction is $\leq 35 \%$, QRS duration is $\geq 0.12$ seconds, and there is sinus rhythm ${ }^{[32]}$.

\section{STRATEGIES TO MINIMIZE REQUIREMENT FOR PERMANENT PACEMAKER POST CARDIAC SURGERY}

Given the risks and complications associated with the implantation and maintenance of a PPM, we have outlined a few strategies to minimise its requirement following cardiac surgery. These have been split into preoperative, intraoperative, and postoperative strategies.

Preoperatively, the research has outlined modifiable and non-modifiable risk factors. For example, those considered modifiable include the use of calcium channel blockers ${ }^{[29]}$ and antiarrhythmics ${ }^{[11]}$. Factors which are non-modifiable in this setting include age, gender, and presence of other comorbidities. As such, we recommend optimising and controlling those modifiable risk factors wherever possible without increasing harm to the patient.

Intraoperatively, factors such as prolonged cross-clamping time and CPB duration have been shown to increase the requirement of $\mathrm{PPM}^{[11,17]}$. As such, we recommend optimising surgical procedures to minimise their duration. Furthermore, diuretic use during surgery was found as an independent predictor of PPM following cardiac surgery ${ }^{[2]}$. We recommend clinicians find alternative and equally efficacious therapies to minimise PPM requirement.

Lastly, postoperative risk factors include electrolyte disorders and redo operations ${ }^{[22,42]}$. As such, we recommend checking for electrolyte disturbances prior to surgery and wherever necessary and possible, correcting it. 


\section{CONCLUSION}

The rate of PPM implantation is procedure-specific. Optimization of perioperative factors can lead to a significant reduction in the rate of insertion of PPM. Early recognition of PPM insertion is crucial to avoid unnecessary delayed discharge from the hospital and potential cost savings.

\section{No financial support.}

No conflict of interest.

\section{Authors' roles \& responsibilities}

$\mathrm{AH}$

Substantial contributions to the conception or design of the work; or the acquisition, analysis, or interpretation of data for the work; drafting the work or revising it critically for important intellectual content; final approval of the version to be published

Substantial contributions to the conception or design of the work; or the acquisition, analysis, or interpretation of data for the work; drafting the work or revising it critically for important intellectual content; final approval of the version to be published

AN Substantial contributions to the conception or design of the work; or the acquisition, analysis, or interpretation of data for the work; drafting the work or revising it critically for important intellectual content; final approval of the version to be published

Substantial contributions to the conception or design of the work; or the acquisition, analysis, or interpretation of data for the work; drafting the work or revising it critically for important intellectual content; final approval of the version to be published

MK

Substantial contributions to the conception or design of the work; or the acquisition, analysis, or interpretation of data for the work; drafting the work or revising it critically for important intellectual content; final approval of the version to be published

ADM Substantial contributions to the conception or design of the work; or the acquisition, analysis, or interpretation of data for the work; drafting the work or revising it critically for important intellectual content; final approval of the version to be published

\section{REFERENCES}

1. Steyers CM 3rd, Khera R, Bhave P. Pacemaker Dependency after Cardiac Surgery: A Systematic Review of Current Evidence. PLoS One. 2015;10(10):e0140340. doi: 10.1371/journal.pone.0140340.

2. Turkkan C, Osmanov D, Yildirim E, Ozcan KS, Altay S, Hasdemir H, et al. Bradyarrhythmia development and permanent pacemaker implantation after cardiac surgery. North Clin Istanb. 2018;5(4):288-294. doi: 10.14744/ nci.2017.20438.
3. Gordon RS, Ivanov J, Cohen G, Ralph-Edwards AL. Permanent cardiac pacing after a cardiac operation: predicting the use of permanent pacemakers. Ann Thorac Surg. 1998;66(5):1698-704. doi: 10.1016/ s0003-4975(98)00889-3.

4. Raza SS, Li JM, John R, Chen LY, Tholakanahalli VN, Mbai M, et al. Longterm mortality and pacing outcomes of patients with permanent pacemaker implantation after cardiac surgery. Pacing Clin Electrophysiol. 2011;34(3):331-8. doi: 10.1111/j.1540-8159.2010.02972.x.

5. Schurr UP, Berli J, Berdajs D, Häusler A, Dzemali O, Emmert M, et al. Incidence and risk factors for pacemaker implantation following aortic valve replacement. Interact Cardiovasc Thorac Surg. 2010;1 1(5):556-60. doi: 10.1510/icvts.2010.249904.

6. Huynh H, Dalloul G, Ghanbari H, Burke P, David M, Daccarett M, et al. Permanent pacemaker implantation following aortic valve replacement: current prevalence and clinical predictors. Pacing Clin Electrophysiol. 2009 Dec;32(12):1520-5. doi: 10.1111/j.1540-8159.2009.02552.x.

7. Jokinen JJ, Turpeinen AK, Pitkänen O, Hippeläinen MJ, Hartikainen JE. Pacemaker therapy after tricuspid valve operations: implications on mortality, morbidity, and quality of life. Ann Thorac Surg. 2009;87(6):180614. doi: 10.1016/j.athoracsur.2009.03.048.

8. Mar PL, Angus CR, Kabra R, Migliore CK, Goswami R, John LA, et al. Perioperative predictors of permanent pacing and long-term dependence following tricuspid valve surgery: a multicentre analysis. Europace. 2017;19(12):1988-1993. doi: 10.1093/europace/euw391.

9. Elahi MM, Lee D, Dhannapuneni RR. Predictors of permanent pacemaker implantation during the early postoperative period after valve surgery. Tex Heart Inst J. 2006;33(4):455-7.

10. Erdogan HB, Kayalar N, Ardal H, Omeroglu SN, Kirali K, Guler M, Akinci E, Yakut C. Risk factors for requirement of permanent pacemaker implantation after aortic valve replacement. J Card Surg. 2006;21(3):2115; discussion 216-7. doi: 10.1111/j.1540-8191.2006.00216.x.

11. Merin O, Ilan M, Oren A, Fink D, Deeb M, Bitran D, Silberman S. Permanent pacemaker implantation following cardiac surgery: indications and long-term follow-up. Pacing Clin Electrophysiol. 2009;32(1):7-12. doi: 10.1111/j.1540-8159.2009.02170.x.

12. Piantá RM, Ferrari AD, Heck AA, Ferreira DK, Piccoli Jda C, Albuquerque LC, et al. Atrioventricular block in coronary artery bypass surgery: perioperative predictors and impact on mortality. Rev Bras Cir Cardiovasc. 2015;30(2):164-72. doi: 10.5935/1678-9741.20140086.

13. Dawkins S, Hobson AR, Kalra PR, Tang AT, Monro JL, Dawkins KD. Permanent pacemaker implantation after isolated aortic valve replacement: incidence, indications, and predictors. Ann Thorac Surg. 2008;85(1):108-12. doi: 10.1016/j.athoracsur.2007.08.024.

14. Guglielmetti L, Nazif T, Sorabella R, Akkoc D, Kantor A, Gomez A, et al. Bicuspid aortic valve increases risk of permanent pacemaker implant following aortic root replacement. Eur J Cardiothorac Surg. 2016;50(3):497-503. doi: 10.1093/ejcts/ezw044.

15. Limongelli G, Ducceschi V, D'Andrea A, Renzulli A, Sarubbi B, De Feo $M$, et al. Risk factors for pacemaker implantation following aortic valve replacement: a single centre experience. Heart. 2003;89(8):901-4. doi: 10.1136/heart.89.8.901.

16. Baerman JM, Kirsh MM, de Buitleir M, Hyatt L, Juni JE, Pitt B, et al. Natural history and determinants of conduction defects following coronary artery bypass surgery. Ann Thorac Surg. 1987;44(2):150-3. doi: 10.1016/ s0003-4975(10)62027-9.

17. Emlein G, Huang SK, Pires LA, Rofino K, Okike ON, Vander Salm TJ. Prolonged bradyarrhythmias after isolated coronary artery bypass graft surgery. Am Heart J. 1993;126(5):1084-90. doi: 10.1016/00028703(93)90658-v.

18. Onalan O, Crystal A, Lashevsky I, Khalameizer V, Lau C, Goldman B, et 
al. Determinants of pacemaker dependency after coronary and/or mitral or aortic valve surgery with long-term follow-up. Am J Cardiol. 2008;101(2):203-8. doi: 10.1016/j.amjcard.2007.07.062.

19. Caspi J, Amar R, Elami A, Safadi T, Merin G. Frequency and significance of complete atrioventricular block after coronary artery bypass grafting. Am J Cardiol. 1989;63(9):526-9. doi: 10.1016/0002-9149(89)90893-x.

20. Mosseri M, Meir G, Lotan C, Hasin Y, Applebaum A, Rosenheck S, et al. Coronary pathology predicts conduction disturbances after coronary artery bypass grafting. Ann Thorac Surg. 1991;51(2):248-52. doi: 10.1016/0003-4975(91)90796-s.

21. Mustonen P, Hippeläinen M, Vanninen E, Rehnberg S, TenhunenEskelinen M, Hartikainen J. Significance of coronary artery bypass grafting-associated conduction defects. Am J Cardiol. 1998;81 (5):558-63. doi: 10.1016/s0002-9149(97)00981-8.

22. Gundry SR, Sequeira A, Coughlin TR, McLaughlin JS. Postoperative conduction disturbances: a comparison of blood and crystalloid cardioplegia. Ann Thorac Surg. 1989;47(3):384-90. doi: 10.1016/00034975(89)90378-0.

23. Glikson M, Dearani JA, Hyberger LK, Schaff HV, Hammill SC, Hayes DL. Indications, effectiveness, and long-term dependency in permanent pacing after cardiac surgery. Am J Cardiol. 1997;80(10):1309-13. doi: 10.1016/s0002-9149(97)00671-1.

24. Nardi P, Pellegrino A, Scafuri A, Bellos K, De Propris S, Polisca P, et al. Permanent pacemaker implantation after isolated aortic valve replacement: incidence, risk factors and surgical technical aspects. J Cardiovasc Med (Hagerstown). 2010;11(1):14-9. doi: 10.2459/ JCM.0b013e32832f9fde.

25. Meimoun P, Zeghdi R, D'Attelis N, Berrebi A, Braunberger E, Deloche A, et al. Frequency, predictors, and consequences of atrioventricular block after mitral valve repair. Am J Cardiol. 2002;89(9):1062-6. doi: 10.1016/ s0002-9149(02)02276-2.

26. DeRose JJ Jr, Mancini DM, Chang HL, Argenziano M, Dagenais F, Ailawadi $\mathrm{G}$, et al. Pacemaker Implantation After Mitral Valve Surgery With Atrial Fibrillation Ablation. J Am Coll Cardiol. 2019;73(19):2427-2435. doi: 10.1016/j.jacc.2019.02.062.

27. Koplan BA, Stevenson WG, Epstein LM, Aranki SF, Maisel WH. Development and validation of a simple risk score to predict the need for permanent pacing after cardiac valve surgery. J Am Coll Cardiol. 2003;41(5):795-801. doi: 10.1016/s0735-1097(02)02926-1.

28. Al-Ghamdi B, MallawiY, Shafquat A, Ledesma A, AlRuwaili N, Shoukri M, et al. Predictors of Permanent Pacemaker Implantation After Coronary Artery Bypass Grafting and Valve Surgery in Adult Patients in Current Surgical Era. Cardiol Res. 2016;7(4):123-129. doi: 10.14740/cr480w.

29. Lewis JW Jr, Webb CR, Pickard SD, Lehman J, Jacobsen G. The increased need for a permanent pacemaker after reoperative cardiac surgery. J Thorac Cardiovasc Surg. 1998;116(1):74-81. doi: 10.1016/S00225223(98)70245-4.

30. Mar PL, Angus CR, Kabra R, Migliore CK, Goswami R, John LA, et al. Perioperative predictors of permanent pacing and long-term dependence following tricuspid valve surgery: a multicentre analysis. Europace. 2017;19(12):1988-1993. doi: 10.1093/europace/euw391.

31. Kusumoto FM, Goldschlager N. Cardiac pacing. N Engl J Med. 1996;334(2):89-97. doi: 10.1056/NEJM199601113340206.

32. Epstein AE, DiMarco JP, Ellenbogen KA, Estes NA 3rd, Freedman RA, Gettes LS, et al. ACC/AHA/HRS 2008 Guidelines for Device-Based Therapy of Cardiac Rhythm Abnormalities: a report of the American College of Cardiology/American Heart Association Task Force on Practice Guidelines (Writing Committee to Revise the ACC/AHA/NASPE 2002 Guideline Update for Implantation of Cardiac Pacemakers and Antiarrhythmia Devices) developed in collaboration with the American
Association for Thoracic Surgery and Society of Thoracic Surgeons. J Am Coll Cardiol. 2008;51(21):e1-62. doi: 10.1016/j.jacc.2008.02.032. Erratum in: J Am Coll Cardiol. 2009;53(16):1473. Erratum in: J Am Coll Cardiol. 2009 Jan 6;53(1):147.

33. Dreifus LS, Fisch C, Griffin JC, Gillette PC, Mason JW, Parsonnet V. Guidelines for implantation of cardiac pacemakers and antiarrhythmia devices. A report of the American College of Cardiology/American Heart Association Task Force on Assessment of Diagnostic and Therapeutic Cardiovascular Procedures (Committee on Pacemaker Implantation). J Am Coll Cardiol. 1991;18(1):1-13. doi: 10.1016/s0735-1097(10)80209-8.

34. Madigan JD, Choudhri AF, Chen J, Spotnitz HM, Oz MC, Edwards N. Surgical management of the patient with an implanted cardiac device: implications of electromagnetic interference. Ann Surg. 1999;230(5):63947. doi: 10.1097/00000658-199911000-00005.

35. Ozcan KS, Osmonov D, Altay S, Dönmez C, Yıldırım E, Türkkan C, et al. Pacemaker implantation complication rates in elderly and young patients. Clin Interv Aging. 2013;8:1051-4. doi: 10.2147/CIA.S47121.

36. Mukaka MM. Statistics corner: A guide to appropriate use of correlation coefficient in medical research. Malawi Med J. 2012;24(3):69-71.

37. Carrión-Camacho MR, Marín-León I, Molina-Doñoro JM, González-López JR. Safety of Permanent Pacemaker Implantation: A Prospective Study. J Clin Med. 2019;8(1):35. doi: 10.3390/jcm8010035.

38. Farmer DM, Estes NA 3rd, Link MS. New concepts in pacemaker syndrome. Indian Pacing Electrophysiol J. 2004;4(4):195-200.

39. Baraki H, Al Ahmad A, Jeng-Singh S, Saito S, Schmitto JD, Fleischer B, et al. Pacemaker dependency after isolated aortic valve replacement: do conductance disorders recover over time? Interact Cardiovasc Thorac Surg. 2013;16(4):476-81. doi: 10.1093/icvts/ivs555.

40. Kim MH, Deeb GM, Eagle KA, Bruckman D, Pelosi F, Oral H, et al. Complete atrioventricular block after valvular heart surgery and the timing of pacemaker implantation. Am J Cardiol. 2001;87(5):649-51, A10. doi: 10.1016/s0002-9149(00)01448-X.

41. Berdajs D, Schurr UP, Wagner A, Seifert B, Turina MI, Genoni M. Incidence and pathophysiology of atrioventricular block following mitral valve replacement and ring annuloplasty. Eur J Cardiothorac Surg. 2008;34(1):55-61. doi: 10.1016/j.ejcts.2008.03.051.

42. Klapkowski A, Pawlaczyk R, Kempa M, Jagielak D, Brzeziński M, Rogowski J. Complete atrioventricular block after isolated aortic valve replacement. Kardiol Pol. 2016;74(9):985-93. doi: 10.5603/KP.a2016.0038.

43. Elahi MM, Osman KA, Bhandari M, Dhannapuneni RR. Does the type of prosthesis influence the incidence of permanent pacemaker implantation following isolated aortic valve replacement. Heart Surg Forum. 2005;8(6):E396-400. doi: 10.1532/HSF98.20051025.

44. Aydin E, Arslan A, Ozkokeli M. Comparison of superior septal approach with left atriotomy in mitral valve surgery. Rev Bras Cir Cardiovasc. 2014;29(3):367-73. doi: 10.5935/1678-9741.20140045.

45. García-Villarreal OA, González-Oviedo R, Rodríguez-González H, Martínez-Chapa HD. Superior septal approach for mitral valve surgery: a word of caution. Eur J Cardiothorac Surg. 2003;24(6):862-7. doi: 10.1016/ s1010-7940(03)00613-4.

46. Lukac P, Hjortdal VE, Pedersen AK, Mortensen PT, Jensen HK, Hansen PS. Superior transseptal approach to mitral valve is associated with a higher need for pacemaker implantation than the left atrial approach. Ann Thorac Surg. 2007:83(1):77-82. doi: 10.1016/j.athoracsur.2006.08.034.

47. Masuda M, Tominaga R, Kawachi Y, Fukumura F, Morita S, Imoto Y, et al. Postoperative cardiac rhythms with superior-septal approach and lateral approach to the mitral valve. Ann Thorac Surg. 1996;62(4):111822. doi: 10.1016/0003-4975(96)00379.

48. Nienaber JJ, Glower DD. Minitransseptal versus left atrial approach to the mitral valve: a comparison of outcomes. Ann Thorac Surg. 
2006;82(3):834-9; discussion 839. doi: 10.1016/j.athoracsur.2006.04.014. 49. Rezahosseini O, Rezaei M, Ahmadi Tafti SH, Jalali A, Bina P, Ghiasi A, et al. Transseptal Approach versus Left Atrial Approach to Mitral Valve: A Propensity Score Matching Study. JTehran Heart Cent. 2015;10(4):188-93.

50. Tenpaku H, Wariishi S, Kanemitsu N, Okabe M, Nakamura T. Combined superior-transseptal approach versus conventional approach for mitral valve surgery. Jpn J Thorac Cardiovasc Surg. 2000;48(11):688-92. doi: 10.1007/BF03218233.

51. Utley JR, Leyland SA, Nguyenduy T. Comparison of outcomes with three atrial incisions for mitral valve operations. Right lateral, superior septal, and transseptal. J Thorac Cardiovasc Surg. 1995;109(3):582-7. doi: 10.1016/S0022-5223(95)70292-X.

\section{ERRATUM}

In the article "Permanent Pacemaker Post Cardiac Surgery: where do we Stand?", with DOI code http://dx.doi.org/10.21470/1678-9741-2020-0054, published in the Brazilian Journal of Cardiovascular Surgery, ePub ahead of print on September, 2020, the surname of the second author is misspelled:

In the original version the information was:

Amer Harky',2,3, MBChB, MSc, MRCS; Francesca Gaetta', MD; Arish Noshirwani', MD; Shubhi Gutpa3; Muhammed Kermali ${ }^{4}$, MD; Andrew D Muir ${ }^{1}$, MD

The correct information is:

Amer Harky ${ }^{1,2,3}$, MBChB, MSc, MRCS; Francesca Gatta', MD; Arish Noshirwani', MD; Shubhi Gutpa3; Muhammed Kermali ${ }^{4}$, MD; Andrew D Muir ${ }^{1}$, MD 